\title{
Neurosurgical and Clinical Relevance of Microsurgical Anatomy of Cerebellar Para Floccular Perforating Space
}

\author{
Sosa Pablo ${ }^{1-3}$, Dujovny Manuel ${ }^{2 *}$, Gonzales López Pablo ${ }^{3}$, Eduardo Fernández ${ }^{4}$ and Pedro Moreno López ${ }^{3}$ \\ ${ }^{1}$ Department of Neurosurgery, Central Hospital, Mendoza, Argentina \\ ${ }^{2}$ Department of Neurosurgery, Wayne State University, Detroit, Michigan \\ ${ }^{3}$ Department of Neurosurgery, University Hospital of Alicante, Alicante, Spain \\ ${ }^{4}$ Institute of Bioengineering and Department of Anatomy and Histology University, Miguel Hernandez and CIBER BBN, Alicante, Spain
}

Received: 阱 August 28, 2018; Published: 眥 August 31, 2018

*Corresponding author: Manuel Dujovny, Department of Neurosurgery, Wayne State University, Detroit, Michigan, USA

\begin{abstract}
The cerebellopontine angle (CPA) is a complex, neurovascular area where neoplasms and microvascular pathologies befall. Surgical treatment within the CPA demonstrates the potential risk for ischemic complications within the brainstem and cerebellum. The etiologies of these vascular complications remain unclear, but recent anatomical studies potentially could explain the origin of these events. We reviewed the recent findings and concluded the importance in protecting the perforating vessels during surgical intervention for all pathologies within the CPA.
\end{abstract}

Keywords: Perforating Vessels; Para floccular Perforating Space; Middle Cerebellar Peduncle

Abbreviations: Cerebellopontine Angle (CPA); Anterior Inferior Cerebellar Artery (AICA)

\section{Review}

The surgical interventions for vascular and tumoral pathologies found in the cerebellopontine angle (CPA) have potential complications of brainstem and cerebellar ischemia, and may be asymptomatic or symptomatic with devastating consequences [1-3]. The most common tumors in the CPA are the vestibular schwannomas', meningiomas, and epidermoid cyst, but it is not uncommon to see metastasized lesions, chordomas, cholesteatoma, and hamartomas within this area [4-6]. Surgical resection of some pathologies have been associated with certain vascular complications presenting as stroke findings near the surrounding structures. Consequently, tumors of the cerebellopontine angle have been associated with variable rates of postoperative facial palsy and hearing loss. The vascular pathologies of the CPA may involve microvascular compression of the cranial nerves or aneurysms. Both pathologies have been associated in the potential ischemic complications [7-12]. It is known, that a pure anterior inferior cerebellar artery (AICA) infarct affects the lateral pons, middle cerebellar peduncle, and cerebellar flocculus, and the clinical findings of a neurological examination is remarkable for early detection of some physical presentations including; facial weakness, dysarthria, dysmetria, vertigo, ataxia, horizontal nystagmus, or hearing loss. The middle cerebellar peduncle was the core of the affected territory in AICA strokes and was suggested as the radiological hallmark of this vascular insult, as was described by Amarenco $[13,14]$.

In a previously conducted study by Sosa et al., they described the microvascular anatomy of parafloccular perforating space, as the triangular-shaped cisternal surface of the middle cerebellar peduncle between the superior and inferior cerebellopontine fissures that extends laterally to the fissure apex and wraps 
medially over the flocculus. These areas are the entry point for many perforating vessels of the anterior inferior cerebellar artery, with a minimum of 15 to a maximum of 26 vessels per parafloccular perforating space, toward the middle cerebellar peduncle and lateral brainstem. The outer diameter of the perforating artery was $0.11 \mathrm{~mm}$ and the length were $2.84 \mathrm{~mm}$. Before the entrance into the neural tissue, these vessels would send branches to the cisternal portion of the cranial nerves and provide vasa nervorum to the facial and vestibulocochlear nerves. These findings provide anatomical knowledge of the vascular structures that could explain the potential origin of ischemic insult during surgeries of the CPA [15].

In literature, some articles reported vascular ischemic complications that could be associated with lesions of the perforating vessels. Sarkar and Link [16]. they described a distal AICA aneurysm clipping with postsurgical increase in nystagmus and ataxia and findings on MRI of middle cerebellar peduncle stroke. Kenia et al. [17]. observed vascular complications occurring after acoustic neuroma surgery and was confined to the middle cerebellar peduncle and were associated with AICA syndrome with an unusual nystagmus. Hollon et al. [18] described brainstem ischemia after vestibular schwannoma surgery and found that the risk factor identified for microvascular brainstem ischemia was the trans labyrinthine approach and may result from intraoperative injury of recurrent perforating arteries of anterior inferior cerebellar artery branches. The symptoms that were experienced by some patients included dysmetria, nystagmus, and vertigo and was associated with ischemic finding in parafloccular space shown in an MRI [18].

In our previous work, we observed in cadaveric dissection the vascular territory of irrigation of these perforating arteries of the anterior inferior cerebellar artery. This territory corresponds with the middle cerebellar peduncle. These perforating vessels send branches to the seventh and eighth cranial nerve and could be injured during surgery and be associated with alterations of the cranial nerves. In the same way, when injured, they can be associated with ischemia of the middle cerebellar peduncle. In the clinical finding, unpublished data, we observed in the postoperative MRI of the patient under surgery of the CPA lesions, areas of ischemia involving the superficial and deep middle cerebellar peduncle. We observed these vascular changes in the patients under the restrosigmoid approach. In accordance with minor symptoms described by other authors, our primary information of this unpublished data found similar findings.

In conclusion, while efforts should be made to preserve perforating vessels to avoid ischemic events and decrease the morbidity during cerebellopontine angle surgery. The importance of considering small perforating vessels during surgery of the CPA, is related that the tumors in this area can compress, stretch, or completely incorporate the perforating vessels or their trunks and can be confused by the surgeon.

\section{References}

1. Shrontz C, Dujovny M, Ausman JI, Diaz FG, Pearce JE, et al (1986) Surgical anatomy of the arteries of the posterior fossa. J Neurosurg 65(4): 540544 .

2. Kim HN, Kim YH, Park IY, Kim GR, Chung IH (1990) Variability of the surgical anatomy of the neurovascular complex of the cerebellopontine angle. Ann Otol Rhinol Laryngol 99(4 Pt 1): 288-296.

3. Rhoton AL Jr (2000) The cerebellopontine angle and posterior fossa cranial nerves by the retrosigmoid approach. Neurosurgery 47 (3 Suppl): 93-129.

4. Calzada AP, Go JL, Tschirhart DL, Brackmann DE, Schwartz MS (2015) Cerebellopontine angle and intracanalicular masses mimicking vestibular schwannomas. Otol Neurotol 36(3): 491-497.

5. Friedmann DR, Grobelny B, Golfinos JG, Roland JT Jr (2015) Nonschwannoma tumors of the cerebellopontine angle. Otolaryngol Clin North Am 48(3): 461-475.

6. Sosa P, Dujovny M, Cremaschi F, Onyekachi I, Noressia S (2013) Voluntary exile of Pio del Rio Hortega in Buenos Aires, Argentina. Neurocirugia Neurocirugia 22: 31-55

7. Yilmaz C, Altinors N, Sonmez E, Gulsen S, Caner H (2010) Rare lesions of the cerebellopontine angle. Turk Neurosurg 20(3): 390-397.

8. Sanna M, Taibah A, Russo A, Falcioni M, Agarwal M (2004) Perioperative complications in acoustic neuroma (vestibular schwannoma) surgery. Otol Neurotol. 25(3): 379-386.

9. Ansari SF, Terry C, Cohen Gadol AA (2012) Surgery for vestibular schwannomas: a systematic review of complications by approach. Neurosurg Focus 33(3): 14

10. Kunert P, Dziedzic T, Czernicki T, Nowak A, Marchel A (2016) Surgery for sporadic vestibular schwannoma. Part II. Complications (not related to facial and auditory nerves). Neurol Neurochir Pol 50(2): 90-97.

11. Sindou M, Mercier P (2006) Microvascular decompression for hemifacial spasm: Outcome on spasm and complications. A review. Neurochirurgie 64(2): 106-116.

12. Liang Q, Shi X, Wang Y, Sun Y, Wang R, et al. (2012) Microvascular decompression for hemifacial spasm: technical notes on pontomedullary sulcus decompression. Acta Neurochirurgica 154(9): 1621-1626.

13. Amarenco P, Hauw JJ (1990) Cerebellar infarction in the territory of the anterior and inferior cerebellar artery. A clinicopathological study of 20 cases. Brain 113(Pt 1): 139-155.

14. Amarenco P, Rosengart A, DeWitt LD, Pessin MS, Caplan LR (1993) Anterior inferior cerebellar artery territory infarcts. Mechanisms and clinical features. Arch Neurol 50(2): 154-161.

15. Sosa P, Dujovny M, Onyekachi I, Sockwell N, Cremaschi F, et al. (2016) Microvascular anatomy of the cerebellar parafloccular perforating space. J Neurosurg 124(2): 440-449.

16. Sarkar A, Link MJ (2004) Distal anterior inferior cerebellar artery aneurysm masquerading as a cerebellopontine angle tumor: case report and review of literature. Skull Base 14(2): 101-107.

17. Kania R, Lot G, Herman P, Tran Ba Huy P (2003) Vascular complications after acoustic neurinoma surgery. Ann Otolaryngol Chir Cervicofac 120(2): 94-102.

18. Hollon TC, Savastano LE, Argersinger DP, Quint DJ, Thompson BG (2018) Microvascular Brainstem Ischemia After Vestibular Schwannoma Surgery: A Clinical and Microanatomic Study. World Neurosurg 112: 415-424. 
This work is licensed under Creative Commons Attribution 4.0 License

To Submit Your Article Click Here:

Submit Article

DOI: $10.32474 /$ SJO.2018.01.000108

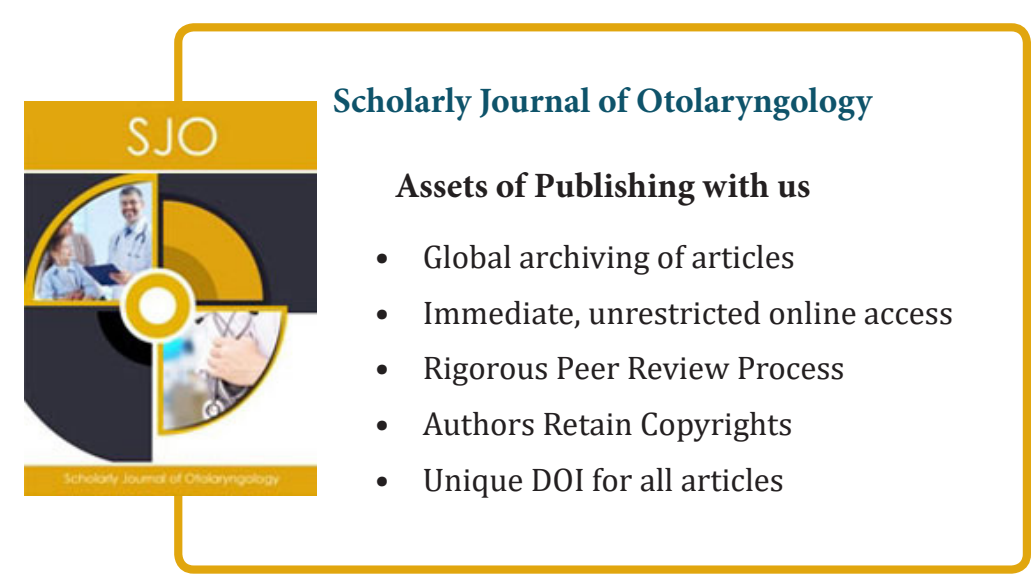

